Family Profile No. 2, 2018

\title{
Coresident Grandparents: Caregivers versus Non-Caregivers
}

Author: Huijing Wu

In 2015, over 72 million individuals were living with at least one grandchild (coresident grandparents). Not all, but many coresident grandparents fill the role of caregiver to their resident grandchildren. Among coresident grandparents, $36 \%$ were caregivers - a slight decrease from 39\% in 2010 (FP-12-18). Using data from the American Community Survey, this profile updates FP-12-18 to examine coresident grandparents and their responsibility for grandchildren by grandparents' age and poverty status as well as how long they have been responsible for their grandchildren. We also examine changes in household structure among grandparent caregivers between 2005 and 2015.

\section{Age Distribution of Grandparent Caregivers vs. Non-Caregivers}

- Grandparent caregivers are younger than non-caregivers, with a median age of 57 and 61, respectively (not shown). Nearly one-fourth (23\%) of caregivers were younger than 50 compared to only $13 \%$ of grandparent non-caregivers.

- Only about one-tenth of grandparent caregivers were aged 70 and older. However, nearly one-quarter of grandparent non-caregivers were aged 70 and older.

Figure 1. Grandparent Caregivers vs. Non-Caregivers by Age Groups, 2015

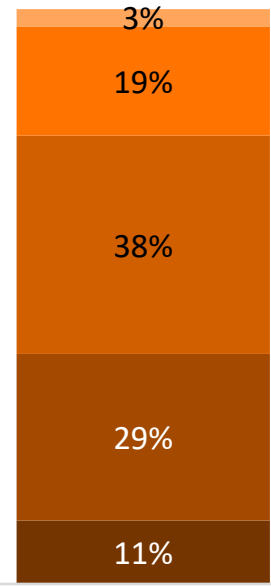

Caregiver

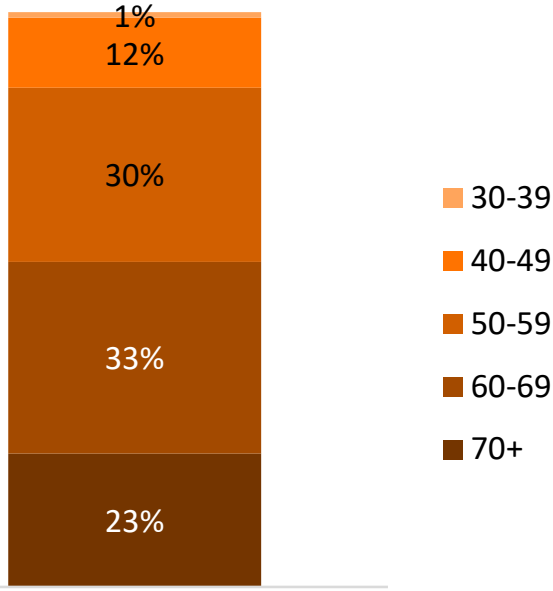

Non-Caregiver

Source: NCFMR analyses of U.S. Census Bureau, American Community Survey, 1-year estimates, 2015

Note: Does not total to $100 \%$ due to rounding.

Economic Disadvantage of Grandparent Caregivers vs. Non-caregivers

- A larger share of grandparent caregivers was economically disadvantaged than non-caregivers. Among grandparent caregivers, $47 \%$ were living in poverty or in a lowincome household compared to $36 \%$ of grandparent non-caregivers.

- The discrepancy was driven by the disproportionate share of grandparent caregivers who were living in poverty-20\%versus $12 \%$ among their non-caregiving counterparts.
Figure 2. Grandparent Caregiver vs. Non-Caregivers by Economic Disadvantage, 2015

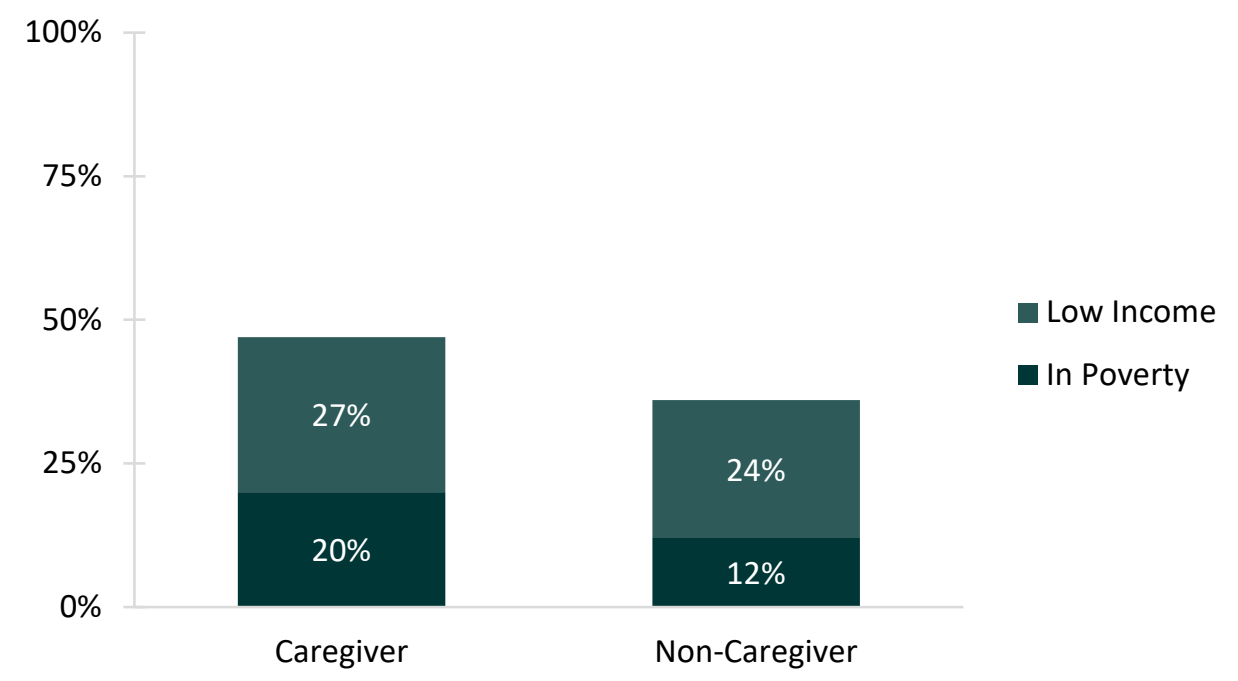

Source: NCFMR analyses of U.S. Census Bureau, American Community Survey, 1-year estimates, 2015 


\section{Grandparent Caregivers' Duration of Responsibility}

Figure 3. Grandparent Caregivers' Duration of Responsibility, 2015

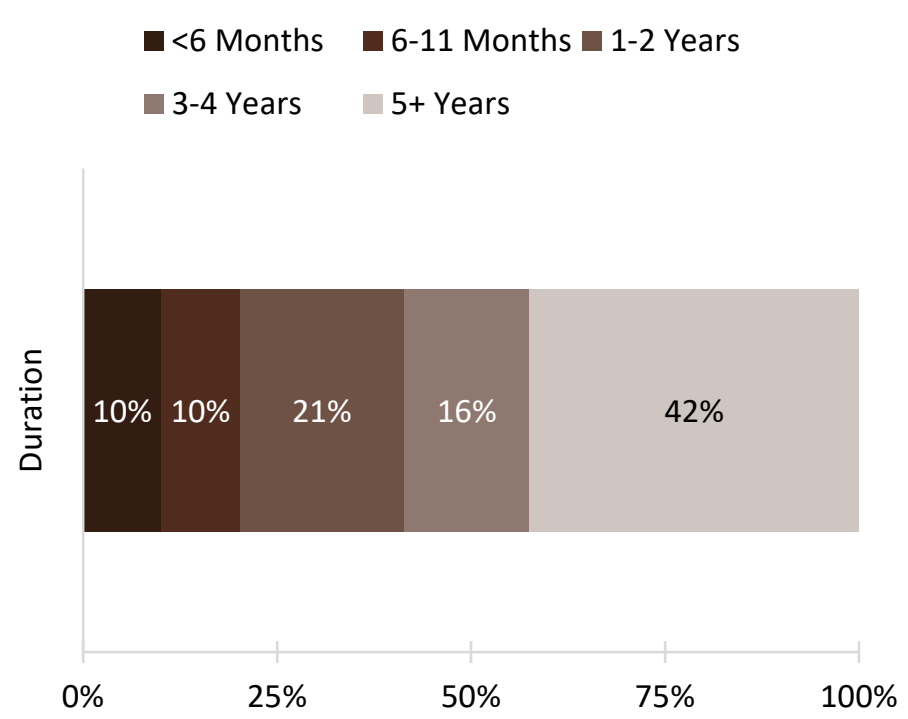

Source: NCFMR analyses of U.S. Census Bureau, American Community Survey, 1-yr est. 2015

Note: Does not total to $100 \%$ due to rounding.

- It is most common for caregiving grandparents to have engaged in this role for five years or more. Two in five (42\%) grandparent caregivers reported they have been responsible for the care of their grandchildren at least five years.

- One in five (20\%) grandparent caregivers have been responsible for less than one year.

\section{Grandparent Caregivers by Household Types}

Figure 4. Grandparent Caregiver by Household Types in 2005, 2010, \& 2015

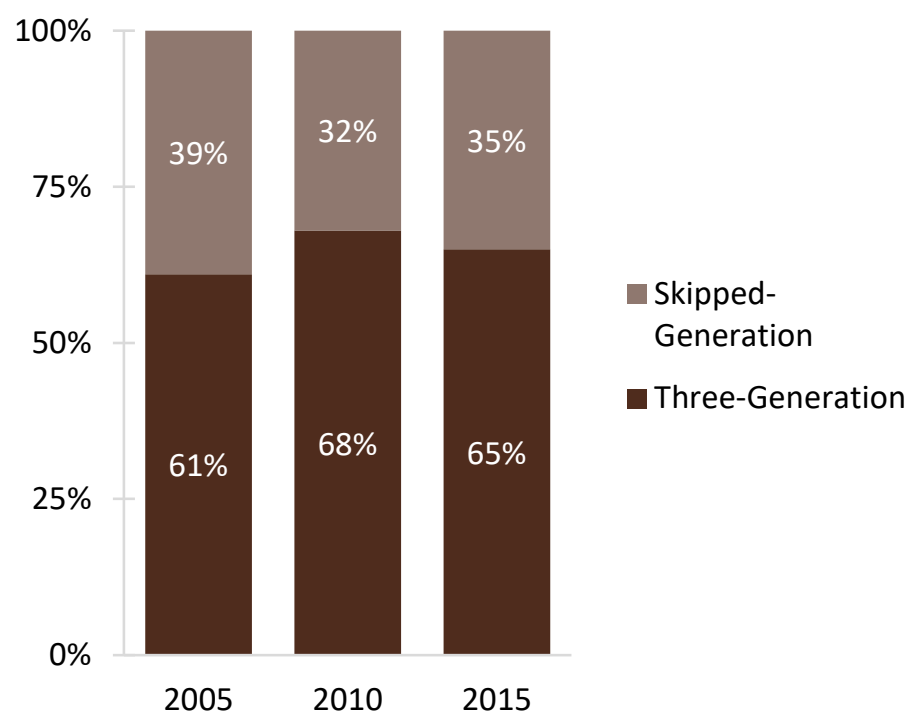

Source: NCFMR analyses of U.S. Census Bureau, American Community Survey, 1-yr est. 2015

- Most grandparent caregivers, at least three out of five, were living with their grandchild and the grandchild's parent (three-generation household). Between 2005 and 2015, there were modest changes.

- In 2005, 39\% of grandparent caregivers lived with their grandchildren in a skipped-generation household (e.g., the grandchild's parent was not present in the household). This percentage declined to 32\% in 2010 but increased slightly to 35\% in 2015.

\section{Data Source:}

Steven Ruggles, Katie Genadek, Ronald Goeken, Josiah Grover, and Matthew Sobek. Integrated Public Use Microdata Series: Version 7.0 [dataset]. Minneapolis, MN: University of Minnesota, 2017. https://doi.org/10.18128/D010.V7.0

\section{References:}

Wilson, B. (2012). Coresident Grandparents: Caregivers Versus Non-Caregivers. Family Profiles, FP-12-18. Bowling Green, OH: National Center for Family \& Marriage Research.

\section{Suggested Citation:}

$\mathrm{Wu}, \mathrm{H}$. (2018). Coresident grandparents: Caregivers versus non-caregivers. Family Profiles, FP-18-02. Bowling Green, OH: National Center for Family \& Marriage Research. https://doi.org/10.25035/ncfmr/fp-18-02.

B O W L I I N G G R E E N S T A t E U N I v E R s I T Y
This project is supported with assistance from Bowling Green State University. From 2007 to 2013, support was also provided by the U.S. Department of Health and Human
Services, Office of the Assistant Secretary for Planning and Evaluation. The opinions and conclusions expressed herein are solely those of the author(s) and should not be construed
as representing the opinions or policy of any agency of the state or federal government.

